\title{
Ramlıç ve Dağlıç Koyunlarda Kırkım Sonu Canlı Ağırlık, Yapağı Verimi ve Özellikleri\#
}

\author{
Özge BAĞKESEN ${ }^{1}$, Serdar KOÇAK ${ }^{2}$ * \\ ${ }^{1}$ Demirci İlce Gıda, Tarm ve Hayvancıllk Müdürlüğ̈, Manisa \\ 2 Afjon Kocatepe Üniversitesi Veteriner Fakültesi Zootekni Anabilim Dall, Afyonkarahisar
}

\#Bu makale birinci yazarın aynı isimli yüksek lisans tezinden özetlenmiştir

*Corresponding author e-mail: serkocak@aku.edu.tr

\begin{abstract}
ÖZ
Bu çalışma, Ramlıç ve Dağlıç ırkı koyunlarda kırkım sonu canlı ağırlık, kirli yapağı verimi ve bazı yapağı özellikleri ile bunları etkileyen faktörlerin incelenmesi amacıyla yapılmıştır. Araştırmada 296 baş Ramlıç, 232 baş Dağlıç koyun ve yapağıları kullanılmıştır. Bu çalışma yetiştirici elindeki 4 farklı sürüde 2015 yllında yürütülmüştür. Ramlıçlarda kırkım sonu canlı ağırlık, kirli yapağı verimi, lüle uzunluğu, elyaf gerçek uzunluğu ve yapağı randımanı genel ortalamaları sırasılla; $64,08 \pm 0,521 \mathrm{~kg}, 3,07 \pm 0,051 \mathrm{~kg}, 5,89 \pm 0,068 \mathrm{~cm}, 8,84 \pm 0,145 \mathrm{~cm}$ ve $\% 73,21 \pm 0,980$ olarak belirlenmiştir. Ramlıçlarda sürünün kirli yapağı verimi, lüle uzunluğu, elyaf gerçek uzunluğu ve yapağı randımanına etkisi önemli $(p<0,05 ; p<0,01 ; p<0,001)$, yaşın ise kırkım sonu canlı ağırlık, kirli yapağı verimi ve elyaf gerçek uzunluğuna etkisi önemli $(p<0,01 ; \quad p<0,001)$ bulunmuştur. Dağllçlarda kırkım sonu canlı ağırlık, kirli yapağı verimi, lüle uzunluğu, elyaf gerçek uzunluğu ve yapağı randımanı genel ortalamalar1 sirasiyla; $47,78 \pm 0,442 \mathrm{~kg}, 1,63 \pm 0,036 \mathrm{~kg}, 9,84 \pm 0,149 \mathrm{~cm}, 13,62 \pm 0,250 \mathrm{~cm}$ ve $\% 73,75 \pm 0,822$ bulunmuştur. Dağlıçlarda sürünün kııkım sonu canlı ağırlık ve lüle uzunluğuna etkisi önemli $(\mathrm{p}<0,001)$, yaşın ise kırkım sonu canlı ağırlık, kirli yapağı verimi ve yapağı randımanına etkisi önemli $(p<0,05 ; \mathrm{p}<0,01 ; \mathrm{p}<0,001)$ bulunmuştur. Sonuç olarak kırkım sonu canlı ağırlık bakımından Ramlıç ırkının orta irilikte, Dağlıçların ise küçük yapılı olduğu ve kırkım sonu canlı ağırllık değerlerinin daha önce yapilan çalışmalarda bildirilen değerlerden yüksek olduğu tespit edilmiş̦tir. Ayrıca elyaf gerçek uzunluğu bakımından Ramlıç yapağılarının kumaş yapımında, Dağlıç yapağılarının ise halı sanayinde kullanılabileceği kanaatine varılmıştır.
\end{abstract}

Anahtar kelimeler: Koyun, Ramlıç, Dağııç, Canlı ağırlık, Yapağı özellikleri

\section{Body Weight After Shearing, Greasy Fleece Weight and Some Fleece Traits of Ramlıç and Dağliç Sheep}

\begin{abstract}
This research was carried out to investigate the body weights after shearing, greasy fleece weight, some fleece traits and the factors affecting them in Dağlıç and Ramlıç sheep. In this study, 296 Ramlıç and 232 Dağlıç sheep and fleece were used. The research was carried out in four farm operation in 2015, Afyonkarahisar, Turkey. Least squares means for body weights after shearing, greasy fleece weight, staple length, fiber length and clean fleece percentage were determined $64,08 \pm 0,521 \mathrm{~kg}, 3,07 \pm 0,051 \mathrm{~kg}, 5,89 \pm 0,068 \mathrm{~cm}, 8,84 \pm 0,145 \mathrm{~cm}$ and $73,21 \pm 0,980 \%$ in Ramliç. The effect of herd for greasy fleece weight, staple length, fiber length and clean fleece percentage were found statistically significant $(p<0,05 ; p<0,01$; $\mathrm{p}<0,001)$. The age of affected body weights after shearing, greasy fleece weight and fiber length $(\mathrm{p}<0,01 ; \mathrm{p}<0,001)$. The general means for body weights after shearing, greasy fleece weight, staple length, fiber length and clean fleece percentage were determined $47,78 \pm 0,442 \mathrm{~kg}, 1,63 \pm 0,036 \mathrm{~kg}, 9,84 \pm 0,149 \mathrm{~cm}, 13,62 \pm 0,250 \mathrm{~cm}$ and $73,75 \pm 0,822 \%$ in Dağliç. The effect of herd for body weights after shearing and staple length were found statistically significant $(\mathrm{p}<0,001)$. The age of affected body weights after shearing, greasy fleece weight and clean fleece percentage $(p<0,05 ; p<0,01 ; p<0,001)$. As a result, the medium size of Ramlıç bred for body weights after shearing and Dağlıç in previous studies although was higher than the reported value was made small compared to other native sheep breeds. Furthermore, it has been concluded that Ramliç fleece in textile and Dağliç fleece can be used in carpet industry.
\end{abstract}

Key words: Sheep, Ramlıç, Dağlıç, Body weight, Fleece traits. 


\section{GİRIŞ}

Hayvancılık sektöründe koyun yetiştiriciliğinin et, süt, yapağı ve deri üretimi bakımından önemli bir yeri vardır. Koyunlardan elde edilen yapağ1, tekstil sanayinin temel hammaddelerinden olup ilk kez M.Ö. 4000' lerde Babilliler tarafindan kumaş yapımında kullanılmıştır. İnsan yaşamında önemli bir yeri olan yapağ1 yaygın olarak tekstil ve halı sanayinde değerlendirilmektedir (Kaymakçı 2006). Türkiye İstatistik Kurumunun verilerine göre 2016 yylında yapağı üretiminin $\% 88,8$ ' i yerli koyun ırklarından karşılanmış ve koyun başına düşen yapağ1 verimi 1,8 kg olmuştur (Anonim 2017). Türkiye yerli koyun ırklarında yapağı verimi, yapağı ve et-yapağı irkları ile kıyaslandığında oldukça düşüktür. Türkiye'deki yerli koyunların et ve yapağ1 verimi ile kalitesinin iyileştirilmesi amacıyla Orta Anadolu Merinosu, Karacabey Merinosu ve Ramlıç ırkları elde edilmiştir. Ramlıç ırk1, 1969 yllında Karacabey Harasından Çifteler Veteriner Zootekni Araştırma Enstitüsüne getirilen Amerika Birleşik Devletleri orijinli Rambouillet ırk1 ile Dağlıç koyunlarının melezleme çalsşmaları sonucunda geliştirilmiştir. Ramlıçlar, \% 65-70 Rambouillet ve \% 30-35 Dağlıç genotipi taşımaktadır (Yalçın 1982). Ramlıçlarda yapılan çalışmalarda kırkım sonu canlı ağırlık, kirli yapağı verimi, lüle uzunluğu ve yapağı randımanı sırasıyla; 39,41-46,94 kg; 2,82-3,17 $\mathrm{kg} ; \quad 6,50-8,00 \mathrm{~cm} \quad$ ve $\%$ 54,00-57,20 olarak bildirilmektedir (Yalçın 1982, Demir 1989a, Demir 1989b, Demir 1995).

Türkiye'nin yerli koyun rrklarından olan Dağlıç'ların, Sakarya Nehri'nden başlayıp Ege bölgesinin k1yı illerine kadar uzanan bölgede özellikle Eskişehir, Afyonkarahisar, Kütahya, Burdur, Ușak, Denizli ve Isparta illerinde yoğun olarak bulunduğu ve Türkiye yerli koyun irkları içerisinde 1980 yllı verilerine göre 7600000 baş ile üçüncü sırada yer aldığı bildirilmektedir (Yalçın 1982, Akçapinar 1994). Son zamanlarda Dağlıç sayısında hızlı bir azalma meydana gelmiştir. Dağlıçlarda yapılan çalışmalarda kırkım sonu canlı ağırlık, kirli yapağı verimi, lüle uzunluğu ve yapağı randimanı sirasiyla; $30,40-39,72 \mathrm{~kg} ; 1,50-2,68 \mathrm{~kg}$; $12,28-22,71 \mathrm{~cm}$ ve $\% 66,40$ olarak bildirilmektedir (Togay ve ark. 1960, Yalçın ve ark.1972, Yalçın ve Ayabakan 1977, Evrim 1978, Başpınar 1985, Demir 1989a, Demir 1989b, Demir 1995, Tekerli ve ark. 2001). Ramlıç ve Dağlıç koyunlarının saf yetiştirme ve seleksiyon yoluyla verimlerinin artırilması amaciyla T.C. Gida, Tarım ve Hayvancilık Bakanlığı, Tarımsal Araştırmalar ve Politikalar Genel Müdürlüğü koordinatörlüğünde Ulusal Küçükbaş Hayvan Islahı Ülkesel Projesi kapsamında Eskişehir ve Afyonkarahisar illerinde 2011 yllında başlayan projeler yürütülmektedir (Tekerli ve ark. 2016, Koçak ve ark. 2016).
$\mathrm{Bu}$ araştırma Afyonkarahisar ilinde yetiştirici elinde bulunan Ramlıç ve Dağlıç koyunlarda kırkım sonu canlı ağırlık, kirli yapağ1 verimi ve bazı yapağ1 özellikleri ile bunları etkileyen faktörlerin incelenmesi amacıyla yapılmıştır.

\section{MATERYAL ve METOT}

\section{Hayvan Materyali}

Araştırma, Afyonkarahisar Merkez, Emirdağ ve Bolvadin ilçelerinde bulunan 296 baş Ramlıç ve 232 baş Dağlıç koyun üzerinde 2015 yılı haziran ayında yürütülmüştür. Bu çalışma 2 adet Ramlıç ve 2 adet Dağlıç sürüsünde yapıllmıştır. Araştırmada kullanılan Ramlıç ve Dağlıç sürüleri Tarımsal Araştırmalar ve Politikalar Genel Müdürlüğü koordinasyonunda yürütülen Halk Elinde Küçükbaş Hayvan Islahı Ülkesel Projesine kayıtlıdır (03RAM2011-01 ve 03DAG2011-01). Bu çalışma Afyon Kocatepe Üniversitesi Hayvan Deneyleri Yerel Etik Kurulu'nun 21.05.2015 tarih ve 49533702/64 sayll yazıs1 ile etik prensiplere uyumlu bulunmuştur.

\section{Yapağı Materyali}

Yapağ1 özelliklerinin belirlenmesi amacıyla 296 baş Ramlıç ve 232 baş Dağlıç koyundan alınan yapağı numunelerinde kirli yapağı verimi ve lüle uzunluğu değerleri belirlenmiştir. Elyaf gerçek uzunluğu ve yapağı randımanı için sürülerde her yaş grubundan $(1,5 ; 2,5 ; 3,5 ; 4$ ve üzeri) 12 ' şer adet olmak üzere 4 sürüde toplam 192 adet yapağı numunesi incelenmiştir.

\section{Bakım ve Besleme}

Koyunların beslenmesinde iklimsel koşullar uygun olduğu kadar meradan yararlanılmıştır. Emirdağ ilçesinde bulunan Ramliç (1 ve 2 ) sürüleri ile Merkez ilçede bulunan Dağlıç (1) sürüsüne meraya ek olarak hayvan başına yaklaşı $0,5 \mathrm{~kg}$ arpa, buğday ve fiğden oluşan rasyon ya da hazır koyun yemi ile birlikte saman verilmiştir. Bolvadin ilçesinde bulunan Dağlıç (2) sürüsünde ise sadece kış mevsiminde hayvan başına yaklaşık $0,5 \mathrm{~kg}$ kesif yem ve saman verilmiştir. Koyunlarda tohumlama Temmuz - Eylül ayları arasında, doğumlar ise Ocak - Mart ayları arasında gerçekleşmiştir.

\section{Metod}

Ramlı̧ ve Dağlıç koyunların sağ tarafinın son kaburga üstünden alınan yapağı numuneleri kilitli poşetlere konularak üzerine koyunun küpe numarası yazılmıştır. $\mathrm{Bu}$ numunelerden yapağ1 randımanı, lüle ve elyaf gerçek uzunluğu ölçümleri yapilmıstır.

Kırkım, Dağlıçlarda kırkım makası, Ramlıçlarda ise kırkım makinası ile yapılmıştır. Kırkım sonrasında canlı ağırlık ve kirli yapağ1 verimi tartılarak 
belirlenmiştir. Lüle uzunluğu, her yapağı numunesi için rastgele seçilen 10 adet lülenin uzunluğu doğal şekli bozulmadan cetvelle ölçülerek elde edilen değerlerin ortalaması, elyaf gerçek uzunluğu ise her yapağı numunesi için rastgele seçilen 100 adet k1l örneği gerdirilmeden, cetvel yardımıyla ölçülerek elde edilen değerlerin ortalaması, "cm" olarak hesaplanmıştır (Akçapınar 1988). Yapağı randımanı için kirli numunelerden 30 gram yapağı örneği ön yıkama, deterjanlı suyla yıkama, sodalı suyla yıkama ve durulama işlemlerinden geçirilmiştir. Oda sıcaklığında bekletilen numuneler daha sonra 105 ${ }^{0} \mathrm{C}$ ' de 6 saat kurutulmuştur. Kurutmadan sonra elde edilen temiz yapağı numuneleri aynı hassas terazi ile tartıldıktan sonra ağırllğı kayıt edilmiştir. Sönmez (1959) tarafından bildirilen formül yardımıyla her numune için yapağı randımanı hesaplanmıştır.

Ramlıç ve Dağlıç ırkları için ayrı olmak üzere kırkım sonu canlı ağıllık, kirli yapağı verimi, yapağı randımanı, lüle ve elyaf gerçek uzunluğunun Variyans analizinde $\mathrm{Y}_{i j k}=\mu+\mathrm{S}_{i}+\mathrm{Y}_{j}+\mathrm{e}_{i j k}$ modeli kullanılmıştır. Bu modelde; $Y_{i j k}$ : Gözlem değerini, $\mu$ : Beklenen ortalama değeri, $S_{i}$ : Sürünün etkisini $\left(_{i}\right.$ $=1$ ve 2$), \mathrm{Y}_{j}$ : Yaşın etkisini $(j=1,5 ; 2,5 ; 3,5 ; 4$ ve üzeri) ve $e_{i j k}$ : Rastgele hatayı ifade etmektedir. Aralarındaki farklılık önemli bulunan grupların karşılaştırılması ise Duncan Testi ile yapılmışır. İstatistiki analizlerde SPSS for Windows programından yararlanılmıştır (Anonim 2009).

\section{BULGULAR}

Bu çalışmada Ramlıç koyunlarda, kırkım sonu canlı ağırlık, kirli yapağı verimi, bazı yapăğ özellikleri ve etkileyen faktörlere ilişkin bulgular Tablo 1' de sunulmuştur. Ramliçlarda kırkım sonu canlı ağırlık, kirli yapağı verimi, lüle uzunluğu, elyaf gerçek uzunluğu ve yapağı randımanı genel ortalamaları sirasiyla; $\quad 64,08 \pm 0,521 \quad \mathrm{~kg}, \quad 3,07 \pm 0,051 \quad \mathrm{~kg}$, $5,89 \pm 0,068 \mathrm{~cm}, 8,84 \pm 0,145 \mathrm{~cm}$ ve $\% 73,21 \pm 0,980$ olarak belirlenmiştir. Sürünün kirli yapağ1 verimi, lüle uzunluğu, elyaf gerçek uzunluğu ve yapağ1 randımanına etkisi önemli $(\mathrm{p}<0,05 ; \mathrm{p}<0,01$; $\mathrm{p}<0,001)$ bulunmuştur. Yaşın ise kırkım sonu canlı ağırlık, kirli yapağı verimi ve elyaf gerçek uzunluğuna etkisi önemli $(p<0,01 ; \quad p<0,001)$ olmuştur.

Dağlıç koyunlarda, kırkım sonu canlı ağırlık, kirli yapağ1 verimi ve bazı yapağ1 özelliklerine ait değerler Tablo 2' de sunulmuştur. Dağlıçlarda kırkım sonu canlı ağırlık, kirli yapağı verimi, lüle uzunluğu, elyaf gerçek uzunluğu ve yapağ1 randımanı genel ortalamaları sirasiyla; $47,78 \pm 0,442$ $\mathrm{kg}, 1,63 \pm 0,036 \mathrm{~kg}, 9,84 \pm 0,149 \mathrm{~cm}, 13,62 \pm 0,250$ $\mathrm{cm}$ ve $\% 73,75 \pm 0,822$ bulunmuştur. Sürünün kırkım sonu canlı ağırlık ve lüle uzunluğuna etkisi önemli $(p<0,001)$ olmuştur. Yaşın kırkım sonu canl1 ağırlık, kirli yapağı verimi ve yapağ1 randımanına etkisi önemli $(\mathrm{p}<0,05 ; \mathrm{p}<0,01$; $\mathrm{p}<0,001)$ bulunmuştur.

Tablo1. Ramlıç Koyunlarda kırkım sonu canlı ağırlık, kirli yapağı verimi ve bazı yapağı özelliklerine ait değerler Table 1. Body weight after shearing, greasy fleece weight and some fleece traits of Ramliç Sheep

\begin{tabular}{|c|c|c|c|c|c|c|c|c|c|c|}
\hline \multirow[t]{2}{*}{ Faktörler } & \multicolumn{2}{|c|}{$\begin{array}{l}\text { Kırkım sonu canlı ağırlık } \\
(\mathrm{kg})\end{array}$} & \multicolumn{2}{|c|}{$\begin{array}{l}\text { Kirli yapağı verimi } \\
(\mathrm{kg})\end{array}$} & \multicolumn{2}{|c|}{$\begin{array}{l}\text { Lüle uzunluğu } \\
\qquad(\mathrm{cm})\end{array}$} & \multicolumn{2}{|c|}{$\begin{array}{l}\text { Elyaf gerçek uzunluğu } \\
\qquad(\mathrm{cm})\end{array}$} & \multicolumn{2}{|c|}{$\begin{array}{c}\text { Yapağı randımanı } \\
(\%)\end{array}$} \\
\hline & $\mathrm{n}$ & $\bar{X} \pm S_{\bar{x}}$ & $\mathrm{n}$ & $\bar{X} \pm S_{\bar{x}}$ & $\mathrm{n}$ & $\bar{X} \pm S_{\bar{x}}$ & $\mathrm{n}$ & $\bar{X} \pm S_{\bar{x}}$ & $\mathrm{n}$ & $\bar{X} \pm S_{\bar{x}}$ \\
\hline$\mu$ & 296 & $64,08 \pm 0,521$ & 296 & $3,07 \pm 0,051$ & 296 & $5,89 \pm 0,068$ & 96 & $8,84 \pm 0,145$ & 96 & $73,21 \pm 0,980$ \\
\hline Sürü & & - & & $* *$ & & $*$ & & $* * *$ & & $* * *$ \\
\hline 1 & 101 & $64,84 \pm 0,837$ & 101 & $3,20 \pm 0,83^{a}$ & 101 & $5,75 \pm 0,109^{b}$ & 48 & $9,47 \pm 0,205^{\text {a }}$ & 48 & $78,46 \pm 1,386^{a}$ \\
\hline 2 & 195 & $63,31 \pm 0,604$ & 195 & $2,93 \pm 0,06^{\mathrm{b}}$ & 195 & $6,03 \pm 0,079$ a & 48 & $8,20 \pm 0,205^{b}$ & 48 & $67,96 \pm 1,386^{b}$ \\
\hline Yaş & & $* * *$ & & $* * *$ & & - & & $* *$ & & - \\
\hline 1,5 & 69 & $57,19 \pm 0,997 \mathrm{c}$ & 69 & $2,92 \pm 0,098^{\mathrm{bc}}$ & 69 & $5,65 \pm 0,130$ & 24 & $8,54 \pm 0,290^{\text {b }}$ & 24 & $74,62 \pm 1,960$ \\
\hline 2,5 & 52 & $63,88 \pm 1,151^{b}$ & 52 & $3,32 \pm 0,114$ a & 52 & $5,94 \pm 0,150$ & 24 & $9,73 \pm 0,290^{a}$ & 24 & $73,78 \pm 1,960$ \\
\hline 3,5 & 70 & $66,10 \pm 1,027$ b & 70 & $3,19 \pm 0,101 \mathrm{ab}$ & 70 & $5,92 \pm 0,134$ & 24 & $8,40 \pm 0,290^{\text {b }}$ & 24 & $72,87 \pm 1,960$ \\
\hline 4 ve üzeri & 105 & $69,14 \pm 0,815^{a}$ & 105 & $2,84 \pm 0,108^{c}$ & 105 & $6,05 \pm 0,107$ & 24 & $8,68 \pm 0,290^{b}$ & 24 & $71,59 \pm 1,960$ \\
\hline
\end{tabular}

-:Önemli değil (p>0,05), * $\mathrm{p}<0,05 ; * *: \mathrm{p}<0,01 ; * * *: \mathrm{p}<0,001$

a, b, c: Aynı sütunda her alt grupta farklı harfleri taşıyan ortalamalar arası farklılıklar önemlidir $(\mathrm{p}<0,05)$. 
Tablo 2. Dağlıç Koyunlarda kırkım sonu canlı ağırlık, kirli yapağı verimi ve bazı yapağı özelliklerine ait değerler Table 2. Body weight after shearing, greasy fleece weight and some fleece traits of Dağlıç Sheep

\begin{tabular}{|c|c|c|c|c|c|c|c|c|c|c|}
\hline Faktörler & \multicolumn{2}{|c|}{$\begin{array}{l}\text { Kırkım sonu canlı } \\
\text { ağırlık (kg) }\end{array}$} & \multicolumn{3}{|c|}{$\begin{array}{l}\text { Kirli yapağ1 verimi } \\
(\mathrm{kg})\end{array}$} & \multirow{2}{*}{$\begin{array}{l}\text { Lüle uzunluğu } \\
\qquad \begin{array}{c}(\mathrm{cm}) \\
\bar{X} \pm S_{\bar{x}} \\
9,84 \pm 0,149\end{array}\end{array}$} & \multicolumn{2}{|c|}{$\begin{array}{l}\text { Elyaf gerçek uzunluğu } \\
\qquad(\mathrm{cm})\end{array}$} & \multicolumn{2}{|c|}{$\begin{array}{c}\text { Yapağı randımanı } \\
(\%)\end{array}$} \\
\hline$\mu$ & $\begin{array}{c}\mathrm{n} \\
232\end{array}$ & $\begin{array}{c}\bar{X} \pm S_{\bar{x}} \\
47,78 \pm 0,442\end{array}$ & $\begin{array}{c}\mathrm{n} \\
232\end{array}$ & $\begin{array}{c}\bar{X} \pm S_{\bar{x}} \\
1,63 \pm 0,036\end{array}$ & $\begin{array}{c}\mathrm{n} \\
232\end{array}$ & & $\begin{array}{l}\mathrm{n} \\
96\end{array}$ & $\begin{array}{c}\overline{\bar{X}} \pm \mathrm{S}_{\bar{x}} \\
13,62 \pm 0,250\end{array}$ & $\begin{array}{c}\mathrm{n} \\
96\end{array}$ & $\begin{array}{c}\bar{X} \pm S_{\bar{x}} \\
73,75 \pm 0,822\end{array}$ \\
\hline Sürü & & $* * *$ & & - & & $* * *$ & & - & & - \\
\hline 1 & 132 & $52,59 \pm 0,555^{a}$ & 132 & $1,63 \pm 0,045$ & 132 & $8,96 \pm 0,187 \mathrm{~b}$ & 48 & $13,41 \pm 0,354$ & 48 & $74,69 \pm 1,163$ \\
\hline 2 & 100 & $42,96 \pm 0,622^{b}$ & 100 & $1,62 \pm 0,051$ & 100 & $10,72 \pm 0,209^{a}$ & 48 & $13,82 \pm 0,354$ & 48 & $72,81 \pm 1,163$ \\
\hline Yaş & & $* * *$ & & $*$ & & - & & - & & $* *$ \\
\hline 1,5 & 48 & $42,33 \pm 0,852 \mathrm{~d}$ & 48 & $1,81 \pm 0,070^{a}$ & 48 & $9,73 \pm 0,287$ & 24 & $13,63 \pm 0,500$ & 24 & $74,44 \pm 1,645^{\mathrm{ab}}$ \\
\hline 2,5 & 40 & $46,64 \pm 0,932^{c}$ & 40 & $1,53 \pm 0,076^{\mathrm{b}}$ & 40 & $9,73 \pm 0,313$ & 24 & $12,82 \pm 0,500$ & 24 & $78,10 \pm 1,645 a$ \\
\hline 3,5 & 29 & $49,43 \pm 1,094^{b}$ & 29 & $1,55 \pm 0,089^{b}$ & 29 & $10,34 \pm 0,368$ & 24 & $13,79 \pm 0,500$ & 24 & $70,68 \pm 1,645^{b}$ \\
\hline 4 ve üzeri & 115 & $52,72 \pm 0,552^{\mathrm{a}}$ & 115 & $1,61 \pm 0,045^{\mathrm{ab}}$ & 115 & $9,56 \pm 0,186$ & 24 & $14,23 \pm 0,500$ & 24 & $71,78 \pm 1,645^{b}$ \\
\hline
\end{tabular}

-:Önemli değil ( $p>0,05), *: p<0,05 ; * *: p<0,01 ; * * *: p<0,001$

a, b, c, d: Aynı sütunda her alt grupta farklı harfleri taşıyan ortalamalar arası farklılıklar önemlidir $(\mathrm{p}<0,05)$.

\section{TARTIŞMA}

Ramlıç koyunlarda kırkım sonu canlı ağıllık genel ortalamas $64,08 \mathrm{~kg}$ tespit edilmiş olup Ramlıç için bildirilen (Demir 1989a, Demir 1995) değerlerden yüksektir. $\mathrm{Bu}$ durum, bakım ve beslemenin iyileştirilmesi ile büyümenin hızlandırılmasına yönelik çalışmalardan kaynaklanmış olabilir. Nitekim Afyonkarahisar ilinde yürütülen "Ramlıç Koyunlarının Halk Elinde Islahı" projesinde 6. ve 12. ay canlı ağırlı̆̆ın yıllar içerisinde yükseldiği bildirilmektedir (Tekerli ve ark. 2016). Ayrıca Ramlıç koyunların kırkım sonu canlı ağırlık genel ortalamas1, Akkaraman (53,5 - 54,7 kg), İvesi (52,9 kg), Kivırcik (45,5), Orta Anadolu Merinosu (60,05 $\mathrm{kg})$ ve Acıpayam $(54,6 \mathrm{~kg})$ koyunları için bildirilen kırkım sonu canlı ağırlı değerlerinden (Sönmez ve ark. 1975, Ünal ve Akçapınar 2001, Elibol ve Dağ 2004, Ünal ve ark. 2004, Yüceer ve ark. 2010) yüksektir. Ramlıç koyun sürülerinde belirlenen kırkım sonu canlı ağırlık değerleri 1. ve 2. sürü için 64,84 ve $63,31 \mathrm{~kg}$ olup aralarındaki farklılık istatistikî olarak önemli değildir. Kırkım sonu canlı ağırlık değerleri 1,$5 ; 2,5 ; 3,5$ ve 4 üzeri yaşlı Ramlıçlar için sırasıyla; 57,19; 63,88; 66,10 ve 69,14 $\mathrm{kg}$ olup gruplar arasindaki farklılık istatistikî bakımdan önemli $(p<0,001)$ bulunmuştur. Yaş ilerledikçe kırkım sonu canlı ağırlık artmaktadır. Bu araştırma sonuçlarına benzer şekilde farklı koyun ırklarında yapılan çalışmalarda kırkım sonu canlı ağırllğa yaşın etkisinin önemli olduğu bildirilmektedir (Elibol ve Dağ 2004, Ünal ve ark. 2004).
$\mathrm{Bu}$ araştırmada Ramlıç koyunların kirli yapağ1 verimi genel ortalamas1 3,07 $\mathrm{kg}$ olarak belirlenmiştir. Bu değer Ramlıç için bildirilen (Yalçın 1982, Demir 1989b, Demir 1995) kirli yapağ1 verimi $(2,82-3,17 \mathrm{~kg})$ aralığındadır. Sürülere göre Ramlıçlarda kirli yapağ1 verimi 1. ve 2 . sürü için 3,20 ve $2,93 \mathrm{~kg}$ tespit edilmiş olup farkll11k istatistikî olarak önemli $(\mathrm{p}<0,01)$ bulunmuştur. Yaş gruplarına göre kirli yapağ1 verim ortalamaları 1,5; 2,5; 3,5 ve 4 üzeri yaşlı Ramlıçlar için sırasıyla; 2,92; $3.32 ; 3,19$ ve $2,84 \mathrm{~kg}$ olarak belirlenmiştir. Yaş grupları arasındaki farklılık istatistikî bakımdan önemlidir $(p<0,001)$. Benzer şekilde farklı koyun ırklarında yapılan çalışmalarda yaşın kirli yapağı verimine etkisinin önemli olduğu bildirilmektedir (Sönmez ve ark. 1975, Çolakoğlu ve Özbeyaz 1999, Ünal ve ark. 2004, Yıldız ve Denk 2006). Ramliç 1rk1 için elde edilen kirli yapağ1 verimi Akkaraman, İvesi, Karayaka ve Kıvırcık ırk1 için bildirilen değerlerden yüksek, Karacabey ve Orta Anadolu Merinosu ile Acıpayam koyunundan düşüktür (Özcan 1970, Öznacar 1973, Sönmez ve ark. 1975, Çolakoğlu ve Özbeyaz 1999, Koyuncu ve ark.1999, Ünal ve Akçapınar 2001, Elibol ve Dağ 2004, Ünal ve ark. 2004, Yildız ve Denk 2006, Garip ve ark. 2010, Yüceer ve ark. 2010).

Ramlı̧clarda lüle uzunluğu genel ortalaması $5,89 \mathrm{~cm}$ olarak hesaplanmıştır. Bu değer Ramlıçlar için bildirilen (Yalçın 1982, Demir 1989b, Demir 1995) lüle uzunluğundan düşük olup bakım, besleme ve ölçüm yönteminin farklilığından kaynaklanmış olabilir. Araştırmanın yürütüldüğü Ramlıç sürülerinde lüle uzunluğu ortalamaları 1. ve 2 . sürü 
için, 5,75 ve $6,03 \mathrm{~cm}$ olup farklılık istatistikî bakımdan önemli $(p<0,05)$ bulunmuştur. Lüle uzunluğu ortalamaları 1,$5 ; 2,5 ; 3,5$ ve 4 üzeri yaşlı Ramlıçlar için sırasıyla; 5,65; 5,94; 5,92 ve 6,05 cm'dir. Yaş grupları arasındaki farklılık istatistikî olarak önemli değildir. Ünal ve ark. (2004) tarafindan yapılan bir çalışmada da lüle uzunluğu bakımından yaş farklılı̆̆ının önemsiz olduğu bildirilmiştir. Ramlıçlar için belirlenen lüle uzunluğu genel ortalaması Akkaraman, Karayaka, Kıvırcık, Anadolu ve Karacabey Merinosu için bildirilen değerlerden düşük olmuştur (Özcan 1970, Sönmez ve ark. 1975, Öznacar 1973, Dellal ve ark. 2000, Y1ldı ve Denk 2006, Gürgen 2008).

Ramlıç koyunlarda elyaf gerçek uzunluğu genel ortalamas1 8,84 cm'dir. Bu değer Akkaraman, İvesi, Karayaka ve Anadolu Merinosu için bildirilen elyaf uzunluğu değerinden düşük, Morkaraman ırkından ise yüksek bulunmuştur (Çolakoğlu ve Özbeyaz 1999, Koyuncu ve ark. 1999, Dellal ve ark. 2000, Küçük ve ark. 2000, Elibol ve Dağ 2004, Gürgen 2008). Bu durum 1rk ve ölçüm yöntemlerinin farklılığından kaynaklanmış olabilir. Ramlıçlarda elyaf gerçek uzunluğu ortalamalar1 1. ve 2. sürü için 9,47 ve $8,20 \mathrm{~cm}$ olup farklılık istatistikî bakımdan önemli $(p<0,001)$ bulunmuştur. Yaş gruplarına göre Ramliç koyunlarda elyaf gerçek uzunluğu ortalamaları 1,$5 ; 2,5 ; 3,5$ ve 4 üzeri yaşlılar için sırasıla; 8,54; 9,73; 8,40 ve 8,68 cm'dir. Yaş grupları arasındaki farklılık istatistikî bakımdan önemlidir $(\mathrm{p}<0,01)$. Bu durum, Küçük ve ark. (2000)' nin yaşın elyaf gerçek uzunluğuna etkisinin önemli olduğu bildirimiyle uyumludur.

Ramlıç koyunlarda yapağı randımanı genel ortalamas1 \% 73,21 olarak tespit edilmiştir. Bu değer Ramlıçlar için bildirilen(Yalçın 1982, Demir 1995) yapağı randımanı değerlerinden (\% 54,0 $57,2)$ yüksektir. Bu durum araştırmalarda kullanılan yöntem farklılı̆̆ından kaynaklanmış olabilir. Ayrıca Akkaraman, Karayaka, Kıvırcık, Morkaraman ve Anadolu Merinosu için bildirilen (Sönmez ve ark. 1975, Çolakoğlu ve Özbeyaz 1999, Koyuncu ve ark. 1999, Dellal ve ark. 2000, Küçük ve ark. 2000, Gürgen 2008, Garip ve ark. 2010) yapağı randımanı değerlerinden de yüksektir. Ramlıç koyunlarda yapağı randımanı ortalamaları 1. ve 2. sürü için \% 78,46 ve 67,96 olup farklılık istatistikî bakımdan önemli $(p<0,001)$ bulunmuştur. Birinci Ramlıç sürüsünde elyaf uzunluğu ve kirli yapağ1 veriminin yüksek olmasının yapağı randımanının artmasına neden olduğu düşünülmektedir. Ramlıç koyunlarda yapağı randımanı ortalamaları 1,$5 ; 2,5 ; 3,5$ ve 4 üzeri yaşlılar için sırasıyla; \% 74,62; 73,78; 72,87 ve 71,59 'tır. Küçük ve ark. (2000)'nın bildirimlerine benzer şekilde yaş grupları arasındaki farklılık istatistikî bakımdan önemli değildir.
Türkiye yerli koyun 1rkları içinde yağlı kuyruklu ve küçük yapılı olarak ifade edilen Dağlıçlarda kırkım sonu canlı ağırlık genel ortalaması 47,78 kg bulunmuştur. Bu değer aynı 1rk için bildirilen (Togay ve ark. 1960, Yalçın ve ark. 1972, Yalçın ve Ayabakan 1977, Evrim 1978, Başpınar 1985, Demir 1989a, Demir 1995) değerlerden (30,4 - 39,7 kg) yüksek olmuştur. Dağlıçlarda belirlenen kırkım sonu canlı ağırlı değerinin daha önceki araştırmalarda bildirilenlerden yüksek olması bakım ve besleme şartlarının iyileştirilmesi ile açıklanabilir. Ayrıca büyümenin hizlandırılmasına yönelik yürütülen çalışmaların canlı ağırlık artışına katk1 sağladığı düşünülmektedir. Nitekim Afyonkarahisar ilinde yürütülen "Dağlıç Koyunlarının Halk Elinde Islahı" projesinde 6. ve 12 . ay canlı ağırlığın yıllar içerisinde yükseldiği bildirilmektedir (Koçak ve ark. 2016). Araştırmanın yapıldı̆̆1 1. ve 2. sürüde kırkım sonu canlı ağırlık ortalamaları 52,59 ve 42,96 kg olarak tespit edilmiştir. Birinci sürü merkez ilçede bulunmakta olup 2. sürüye göre bakım ve besleme imkânları daha iyidir. Dağlıçlarda kırkım sonu canlı ağırlık ortalamaları 1,$5 ; 2,5 ; 3,5$ ve 4 üzeri yaşlı koyunlarda sirasiyla; 42,33; 46,64; 49,43 ve 52,72 kg olmuş ve gruplar arasındaki farklilık önemli $(\mathrm{p}<0,001)$ bulunmuştur. $\mathrm{Bu}$ durum, farklı araştırmalarda kırkım sonu canlı ağırlı̆̆a yaşın etkisinin önemli olduğu bildirimlerine (Elibol ve Dağ 2004, Ünal ve ark. 2004) benzerdir. Dağlıçlarda belirlenen kırkım sonu canlı ağırlık değeri Akkaraman (53,5-54,7 kg), İvesi (52,9 kg) Orta Anadolu Merinosu (60,05 kg) ve Acıpayam (54,6 kg) koyunları için bildirilenlerden (Ünal ve Akçapinar 2001, Elibol ve Dağ 2004, Ünal ve ark. 2004, Yüceer ve ark. 2010) düşüktür. Dağlıç koyunu yerli koyun rrkları içerisinde küçük yapılı bir 1rk olup beklenen bir durumdur.

Dağlıç koyunlarda kirli yapağı verimi genel ortalamas1 1,63 kg olarak hesaplanmıştır. Bu değer farklı araştırmalarda Dağlıçlar için bildirilen (Togay ve ark. 1960, Yalçın ve ark. 1972, Yalçın ve Ayabakan 1977, Başpinar 1985, Demir 1989b, Demir 1995, Tekerli ve ark. 2001) kirli yapağ1 verimi değer (1,50-2,68 kg) aralığındadır. Dağlıç sürülerinde belirlenen kirli yapağı verimi ortalamalar1 1. ve 2 . sürü için 1,63 ve $1,62 \mathrm{~kg}$ olup aralarındaki farklilık istatistikî olarak önemli değildir. Dağlıç koyunlarda kirli yapağ1 verimi 1,5; 2,5; 3,5 ve 4 üzeri yaşlılar için sırasılyla; 1,81; 1,53; 1,55 ve 1,61 kg olmuştur. Yaş grupları arasındaki farklılık istatistikî bakımdan önemli $(p<0,05)$ olup 3,5 yaşına kadar kirli yapağı veriminde bir azalma olduğu görülmektedir. Farklı koyun 1rklarında yapılan çalışmalarda da kirli yapağı verimine yaşın etkisinin önemli olduğu bildirilmektedir (Sönmez ve ark. 1975, Çolakoğlu ve Özbeyaz 1999, Elibol ve Dağ 2004, Ünal ve ark. 2004, Yıldız ve Denk 2006). Dağlıç ırkı için elde edilen kirli yapağı verimi 
Akkaraman, İvesi, Karayaka, Kıvırcık, Karacabey ve Orta Anadolu Merinosu ile Acıpayam koyunundan düşük bulunmuştur (Öznacar 1973, Sönmez ve ark. 1975, Çolakoğlu ve Özbeyaz 1999, Koyuncu ve ark.1999, Ünal ve Akçapinar 2001, Elibol ve Dağ 2004, Ünal ve ark. 2004, Ylldız ve Denk 2006, Gürgen 2008, Garip ve ark. 2010, Yüceer ve ark. 2010).

Dağlıç koyunlarda, lüle uzunluğu genel ortalaması $9,84 \mathrm{~cm}$ bulunmuştur. Bu değer, Dağliçlar için bildirilen (Togay ve ark. 1960, Yalçın ve ark. 1972, Yalçın ve Ayabakan 1977, Evrim 1978, Başpınar 1985, Demir 1989b, Demir 1995) lüle uzunluğu değerlerinden $(12,28-22,71 \mathrm{~cm})$ düşüktür. $\mathrm{Bu}$ durum bakım, besleme ve araştırmalarda kullanılan yöntem farklıllğından kaynaklanmış olabilir. Dağlıç sürülerinde lüle uzunluğu değerleri 1. ve 2 . sürü için 8,96 ve $10,72 \mathrm{~cm}$ olup farklılık istatistikî bakımdan önemli $(p<0,001)$ bulunmuştur. Yaş gruplarına göre Dağlıç koyunlarda lüle uzunluğu ortalamaları 1,$5 ; 2,5 ; 3,5$ ve 4 üzeri yaşlilar için sırasıyla; 9,73; 9,73; 10,34 ve 9,56 cm'dir. Ünal ve ark. (2004)' nin bildirimlerine benzer şekilde lüle uzunluğu bakımından yaş grupları arasındaki farklılık istatistikî olarak önemli değildir. Dağlıçlar için bulunan lüle uzunluğu değeri Akkaraman, Kıvırcık, Karacabey ve Anadolu Merinosundan yüksek, Karayaka 1rkından ise düşük olmuştur (Özcan 1970, Öznacar 1973, Sönmez ve ark. 1975, Dellal ve ark. 2000, Yildız ve Denk 2006, Gürgen 2008).

Dağlıç koyunlarda, elyaf gerçek uzunluğu genel ortalaması 13,62 cm olarak tespit edilmiştir. $\mathrm{Bu}$ değer Karayaka, İvesi ve Akkaraman için bildirilen elyaf uzunluğu değerlerinden düşük, Morkaraman ve Anadolu Merinosu için bildirilen değerlerden yüksek olmuştur (Çolakoğlu ve Özbeyaz 1999, Koyuncu ve ark. 1999, Dellal ve ark. 2000, Küçük ve ark. 2000, Ünal ve Akçapinar 2001, Elibol ve Dağ 2004, Gürgen 2008). Elyaf gerçek uzunluğu ortalamalar1 1. ve 2 . sürü için 13,41 ve $13,82 \mathrm{~cm}$ olup farklılık istatistikî bakımdan önemli değildir. Dağlıç koyunlarda elyaf gerçek uzunluğu ortalamalar1 1,$5 ; 2,5 ; 3,5$ ve 4 üzeri yaşlilar için sirasıyla; 13,$63 ; 12,82 ; 13,79$ ve 14,23 cm'dir. Elyaf gerçek uzunluğu değeri 3,5 yaşından itibaren yükselmiştir. Gürgen (2008) in bildirimlerine benzer şekilde yaş grupları arasındaki farklılık istatistikî bakımdan önemli değildir.

Dağlıç koyunlarda, yapağı randımanı genel ortalamas1 \% 73,75 'dir. Bu değer, Demir (1995) tarafından Dağlıç yapağıları için bildirilen \% 66,4' ten yüksektir. $\mathrm{Bu}$ durum kullanılan yöntem farklılı̆ından kaynaklanmış olabilir. Ayrıca Akkaraman, Karayaka, Kivırcik, Morkaraman ve Anadolu Merinosu yapağıları için bildirilen (Sönmez ve ark. 1975, Çolakoğlu ve Özbeyaz 1999, Koyuncu ve ark. 1999, Dellal ve ark. 2000, Küçük ve ark. 2000, Gürgen 2008, Garip ve ark. 2010) yapağı randımanı değerlerinden de yüksektir. Yapağı randımanı ortalamaları 1. ve 2. sürü için \% 74,69 ve 72,81 olup farklılık istatistikî olarak önemli değildir. Dağlıç koyunlarda yapağı randımanı ortalamaları 1,$5 ; 2,5 ; 3,5$ ve 4 üzeri yaşlılar için sirasiyla; \% 74,44; 78,$10 ; 70,68$ ve 71,78 olup farklılık istatistikî bakımdan önemlidir $(\mathrm{p}<0,01)$.

\section{SONUÇ}

Sonuç olarak Ramlıç ve Dağlıç koyunlarda kırkım sonu canlı ağırlığın daha önceki çalışmalarda aynı rrklar için bildirilen değerlerden yüksek olduğu, Ramlıç ırkının orta irilikte ve Dağlıçların ise küçük yapılı olduğu söylenebilir. Elyaf ve lüle uzunluğu bakımından Ramlıç yapağılarının kumaş üretiminde, Dağlıç yapağılarının ise halı sanayinde kullanılabileceği kanaatine varılmıştır.

\section{TEŞEKKÜR}

$\mathrm{Bu}$ araştırmanın yürütülmesinde desteklerinden dolayı T.C. Gıda Tarım ve Hayvancilık Bakanlığı, Tarımsal Araştırmalar ve Politikalar Genel Müdürlüğü'ne, Halk Elinde Küçükbaş Hayvan Islahı Projesi araştırma ekibi ve teknik elemanları ile yetiştiricilere teşekkür ederiz.

\section{KAYNAKLAR}

Anonim. PASW Statistical Program, Version 18.0, USA, 2009.

Anonim. TÜIK, Hayvansal Üretim İstatistikleri, 2016 Yalı Verileri.

Erişim: [http://www.tuik.gov.tr]. Erişim Tarihi: 21.08.2017.

Akçapınar H. Yapağı bilgisi. Ankara Üniversitesi Veteriner Fakültesi, Teksir 87/88-16, Ankara, 1988.

Akçapınar H. Koyun yetiştiriciliği. Medisan Yayınevi, Ankara, 1994.

Başpınar H. Türkiye'deki başlıca koyun ırklarının yar1-entansif koşullardaki döl, süt ve yapağı verim performansları üzerinde mukayeseli bir araştırma. İstanbul Üniversitesi Veteriner Fakültesi Dergisi, 1985; 11(2): 43-66.

Çolakoğlu N, Özbeyaz C. Akkaraman ve Malya koyunlarının bazı verim özelliklerinin karşılaştırılması. Turkish Journal Of Veterinary and Animal Sciences, 1999; 23: 351-360.

Dellal G, Söylemezoğlu F, Etikan S, Erdoğan Z. Anadolu Merinosu koyunlarının bazı yapağı özellikleri üzerine bir araştırma. Tarım Bilimleri Dergisi, 2000; 6(2): 48-53. 
Demir H. Dağlıç ve Ramlıç koyunlarının önemli verim özellikleri yönünden karşılaştırılması: I. Büyüme, yaşama gücü ve canlı ağırlık. İstanbul Üniversitesi Veteriner Fakültesi Dergisi, 1989a; 15(1): 23-38.

Demir H. Dağlıç ve Ramlıç koyunlarının önemli verim özellikleri yönünden karşılaştırılması: II. Döl verimi, süt verimi ve yapağ1 özellikleri. İstanbul Üniversitesi Veteriner Fakültesi Dergisi, 1989b; 15(1): 39-52.

Demir H. Ramlıç ve Dağlıç koyunlarının melezlenmesi ile elde edilen çeşitli genotiplerin karşılaştırılması. İstanbul Üniversitesi Veteriner Fakültesi Dergisi, 1995; 21(1): 131-141.

Elibol M, Dağ B. Ereğli Koyunculuk Üretme İstasyonunda yetiştirilen Akkaraman, İvesi ve İvesi x Akkaraman melezi $\left(\mathrm{F}_{1}\right.$ ve $\left.\mathrm{IG}_{1}\right)$ koyunlarında kırkım sonu canlı ağırlık ve bazı yapağ1 verim özelliklerini etkileyen faktörlerin parametrelerinin tahmini, S.Ü. Ziraat Fakültesi Dergisi, 2004; 18(34): 1-10.

Evrim M. Dağlıç koyun ırkının verimlerinin seleksiyonla geliştirilme olanakları I. Genel verim düzeyi. İstanbul Üniversitesi Veteriner Fakültesi Dergisi, 1978; 4(1):1-16

Garip M, Coşkun B, Polat ES, Yılmaz A, Tekin ME, Çağlayan T, Kılıç N. Kangal Akkaraman koyunlarında yapağı özellikleri. Eurasian Journal Veterinary Sciences, 2010; 26(2): 93-99.

Gürgen S. Tokat yöresinde yetiştirilen Karayaka koyunlarında yapağı verimi ve bazı fiziksel özellikleri. Gazi Osmanpaşa Üniversitesi, Fen Bilimleri Enstitüsü, Yüksek Lisans Tezi, Tokat, 2008.

Kaymakçı M. İleri Koyun Yetiştiriciliği. Genişletilmiş İkinci Baskı, Bornova-İzmir, 2006

Koçak S, Tekerli M, Erdoğan M, Çelikeloğlu K, Hacan Ö, Bozkurt Z. Halk Elinde Küçükbaş Hayvan Islahı Ülkesel Projesi, Dağlıç koyunlarının halk elinde islahı projesi kesin raporu, T.C. Gida, Tarım ve Hayvancılık Bakanlı̆̆1, Tarımsal Araştırmalar ve Politikalar Genel Müdürlüğ̈̈, 2016.

Koyuncu M, Duru S, Erdoğan T. Karayaka erkek toklularının yapağı verim özellikleri. Hayvansal Üretim Dergisi, 1999; 39(40): 24 29.

Küçük M, Yılmaz O, Ateş CT. Morkaraman, Hamdani ve karagül yapağılarının halı tipi yapağ1 özelliklerine göre değerlendirilmesi. Y.Y.Ü. Veteriner Fakültesi Dergisi, 2000; 11(2): 54-59.
Özcan H. İnanlı İnekhanesinde Kivirc1k koyunlarının beden yapısı, yavru ve yapağ1 verimleri ve önemli yapağ1 karakterleri üzerinde araştırmalar. Ankara Üniversitesi Veteriner Fakültesi Dergisi, 1970; 17(4): 467-483.

Öznacar K. Karacabey Merinoslarında yapağ1 yönünden seleksiyon imkânları. Lalahan Zootekni Arastırma Enstitüsü Dergisi, 1973; 13 (1-2): 3-33.

Sönmez R. Yapağının muayene ve değerlendirilmesinde kullanılan muhtelif metodlar ve bunlarin birbirleri ile mukayesesi. Ankara Üniversitesi Ziraat Fakültesi Yayınları. No:151, Ankara, 1959.

Sönmez R, Alpbaz AG, Sarıcan C, Kızılay E. Kıvırcık koyunlarının süt yönünde ve yapağ1et yönünde saf yetiştirme ve melezleme yolu ile 1slahı, TUBİTAK Projesi kesin raporu, 1975.

Tekerli M, Akcan A, Akıncı Z, Gündoğan M. Akkaraman, Dağlıç, Sakız ve İvesi koyunlarının Afyon koşullarındaki verim özelliklerinin belirlenmesi. TUBİTAKVHAG-1388 ve 98VF02 projeleri kesin raporu, AKÜ Yayın No:34, 2001.

Tekerli M, Koçak S, Erdoğan M, Çelikeloğlu K, Hacan Ö, Bozkurt Z. Halk Elinde Küçükbaş Hayvan Islahı Ülkesel Projesi, Ramlıç koyunlarının halk elinde 1slahı projesi kesin raporu, T.C. Gida, Tarim ve Hayvancılık Bakanlı̆̆ı, Tarımsal Araştırmalar ve Politikalar Genel Müdürlüğü, 2016.

Togay C, Utkanlar N, İmeryüz F, Örkiz M. Çifteler Harası Dağlıç koyunlarının beden ölçüleri ve bazı yapağ1 özellikleri üzerinde araştırmalar. Lalahan Hayvancılık Araştırma Enstitüsü Dergisi, 1960; 10: 54-73.

Ünal N, Akçapınar H. Orta Anadolu Merinoslarında önemli verim özellikleri ve seleksiyonla geliştirilmesi imkânları I. Önemli verim Özelikleri. Lalahan Hayvancılık Araştırma Enstitüsü Dergisi, 2001; 41 (1): 45 - 58

Ünal N, Akçapınar H, Atasoy F, Koçak S, Aytaç M. Akkaraman, Sakız x Akkaraman ve Kivircik x Akkaraman melezleri ( $F_{1}$ ve $\mathrm{G}_{1}$ ) ile Karayaka ve Bafra koyunlarda canlı ağırlık ve yapağı özellikleri. Lalahan Hayvancılık Araştırma Enstitüsü Dergisi, 2004; 44(2): 15-22

Yalçın BC. Rambouillet x Dağlıç melezlemesi ile geliştirilmiş et-yapağ1 yönlü yeni bir koyun tipi: Ramliç. İstanbul Üniversitesi Veteriner Fakültesi Dergisi, 1982; 8(2): 5-15. 
Yalçın BC, Ayabakan Ş. Dağlıç koyunlarının verimlerinin geliştirilmesinde Rambouillet ırkından yararlanma olanakları II. Canlı ağırlık, yapağı verimi ve yapağı özellikleri. İstanbul Üniversitesi Veteriner Fakültesi Dergisi, 1977; 3(1-2): 28-45.

Yalçın BC, Ayabakan Ş, Sincer N, Köseoğlu H. Dağlıç ve Rambouillet $x$ Dağlıç (F1) melezlerinin önemli verim özellikleri bakımından karşılaştııılması. Ankara Üniversitesi Veteriner Fakültesi Dergisi, 1972; 19(3): 371-387.

Yıldız N, Denk H. Van bölgesinde halk elinde yetiştirilen Akkaraman koyunlarının çeşitli verim özelliklerinin araştırılması 2. Kirli yapağ1 verimleri, lüle uzunlukları, beden ölçüleri, kuzuların doğum ağırlıkları ve yaşama güçleri. F.Ü Sağlık Bilimleri Dergisi, 2006; 20(1): 29-37.

Yüceer B, Akçapınar H, Özbaşer FT. Acıpayam Koyunlarında canlı ağırlık ve yapağı özellikleri. Lalahan Hayvancilık Araştırma Enstitüsü Dergisi, 2010; 50(2): 73-80. 